by a doctor. Intramuscular injection both in children and adults is perfectly adequate. We would not agree with the recommendation that cephaloridine should be used as an alternative to penicillin in the treatment of meningococcal infection as recovery is slow following cephaloridine therapy compared with other forms of treatment; chloramphenicol is the alternative drug of choice.

Dr Smith is not correct in stating that pneumococcal meningitis is the next most common form of meningitis in Britain. Haemophilus influenzae meningitis is the second commonest form of bacterial meningitis in Britain and has been for many years. We would agree that treatment with benzylpenicillin is effective in many cases of pneumococcal meningitis but there is good evidence ${ }^{l}$ that cephaloridine is equal, or even superior, to benzylpenicillin in the treatment of this serious condition. Cephaloridine is the treatment of ahoice in the established case and avoids the possibility of penicillin hypersensitivity.

In meningitis due to aerobic Gramnegative rods there is much to be said for the use of gentamicin, perhaps combined with a penicillin or cephalosporin, because it is unusual to find aerobic Gram-negative rods resistant to gentamicin. It is surprising that this drug is not mentioned among the possible alternatives in the article. We would urge that these antibiotics be given initially while laboratory sensitivity tests are being carried out.

We were surprised to see the mention of Mima polymorpha in an article written in 1975 as this organism has clearly been defined as Acinetobacter/Moraxella and has been known as such in Britain for many years.

We are not aware that intratheca isoniazid is regarded as standard treatment in tuberculous meningitis as this drug crosses the blood/brain barrier. When necessary we have found intrathecal streptomycin to be of benefit in the early days of treatment. It is, however, possible that intrathecal therapy with both drugs may be of help in cases which relapse. ${ }^{2}$

Although the article is concerned principally with clinical matters, it is unfortunate that the laboratory diagnosis of herpes simplex meningoencephalitis and toxoplasmosis was not outlined so that readers would know what specimens to take and how they would be dealt with by the laboratory. This is vital step between suspecting the diagnosis from the clinical picture and deciding how to manage the case once the diagnosis has been established.

Department of Laboratory Medicine

R J FALLON

JaMES H LAWSON

Clinical Department of Infectious Diseases Ruchill Hospital,

1 Love, W C, et al, Postgraduate Medical fournal, 2 British Medical fournal, 1971, $1,1$.

SIR,-We feel that the opinion expressed by Dr C C Smith (8 November, p 335) that "systemic corticosteroids, and in particular dexamethasone, should not be given" in the treatment of herpes simplex encephalitis (8 November, p 335) is open to question.

It is true that there are perfectly sound reasons, both virological and clinical, why steroids should be withheld in certain infections caused by members of the herpesvirus group, ${ }^{12}$ but there are equally good reasons to suggest that dexamethasone may be of life-saving importance in the clinical situation resulting from Herpesvirus simplex invasion of the brain. The pathology of this form of viral brain affection is complex, but the clinical neurological and neuropathological evidence indicates that there is significant degree of brain oedema. This oedema constitutes a serious threat to survival and must be controlled if recovery is to begin. The correct management of herpes encephalitis must surely aim at early reduction of this compressive brain oedema, and dexamethasone is one of the effective medical ways of achieving this.

Illis $^{3}$ in his excellent contribution to the Southampton symposium on virus encephalitis, has set out other reasons why this steroid may actually be beneficial in the treatment of herpes encephalitis and not be as harmful as heretofore supposed.

The working party on herpes encephalitis has given careful thought to this problem and on the evidence available concluded that the practical advantages of dexamethasone far outweigh any theoretical arguments agains its use. This steroid has therefore been included in the protocol of a clinical trial of cytosine arabinoside now in progress in 13 centres in the United Kingdom and Belgium. MAURICE LONGSON

North Manchester Regional Virus Laboratory,

Manchester Royal Infirmary,

Manchester

B E JUEL-JENSEN

Department of Communicable Diseases,

Radcliffe Infirmary,

Oxford

L A LIVERSEDG

Department of Neurology,

Manchester Royal Infirmary,

Manchester

1 Longson, M, and Beswick, J S L, Lancet, 1971,

1, 799.
Juel-Jensen, B E, and MacCallum, F O,Herpes Simplex, Varicella, and Zoster, p 132. Hondon, Heinemann, 1972.

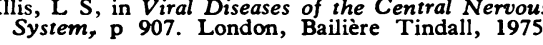

\section{MRC mild hypertension treatment trial}

SIR,-Many of your readers will know that the Medical Research Council is currently conducting a pilot trial to assess the feasibility of a large-scale national trial to determine the best management for mild hypertension. May we use your columns to solicit help in the expansion of this study?

The pilot phase has been in progress for $2 \frac{1}{2}$ years and has already shown the scientific and ethical feasibility of proceeding to the main trial. At present it includes 22 centres (general practices, industrial clinics, and screening organisations) which together have entered 1100 patients, all aged 35-64, with sustained diastolic (phase $\mathrm{V}$ ) pressures within the 90-109-mm $\mathrm{Hg}$ range. These clinics have been selected in terms of known interest and enthusiasm. It is estimated that the full trial would need about 18000 patients, each to be followed for five years. This would probably require the recruitment of about 200 collaborating clinics and the pilot trial should, we believe, include a demonstration that this is possible.
All area medical officers, secretaries of local medical committees, and family practitioner committees (and others) have recently been asked to recommend suitable centres. We hope that this may provide a list of over 200 clinics from which, at this stage, 10 or 15 would be selected by a random method. Recruitment of new centres by this means would show the feasibility of full expansion.

We are seeking practices of at least 7500 patients of whom about 2500 patients will be in the 35-64 age range; $3-5 \%$ of such patients are likely to be suitable for the trial. If any of your readers feel that their own practices-whether general or industrialcould contribute to this trial we would be glad to hear from them. In general practices it has been found that much of the additional work load imposed by the trial can be carried by a suitably trained part-time nurse provided she has ready access to medical advice. The MRC has usually provided funds for such an appointment during the first year, when the screening load is considerable. Once screening and the entry of eligible patients to the trial is completed the follow-up load for a large group practice can be covered by perhaps one doctor session and two nurse sessions a week.

Further details and a copy of the trial protocol can be obtained from: The Secretary, MRC Treatment Trial for Mild Hypertension, MRC/DHSS Epidemiology and Medical Care Unit, Northwick Park Hospital, Watford Road, Harrow HAl 3UJ.

W S PEART Medical Unit, Chairman Medical Unit, London W2

\section{SI units}

SIR,-The recent correspondence in your columns on SI units seems to have been rather one-sided. The prophets of doom have pronounced verbosely from a position of ignorance, for they all appear to condemn the change without having had the experience of using the new system. We hold no brief for promoting SI units; indeed we share your correspondents' doubts on the value or desirability of the change at this time. However, the decision to change was made years ago by committees of considerable eminence, and we as clinicians will have to get used to the system. May we, as general practitioners, record our experience of using SI units over one year since our group laboratory at Cheltenham changed in September 1974? Is it not a fair scientific maxim that knowledge speaks louder than ignorance?

Shortly before the new units were introduced each GP in the area received a fourpage document from the consultant pathologist outlining the history of the Système International and the reasons for the change. $\mathrm{He}$ also gave a short address on the subject at a lunchtime clinical meeting. There was a full explanation of the new units of measurement and a comprehensive list of biochemical values in general use expressed 
in SI units, with comparative old units and conversion factors alongside. As well as this the equivalent result in old units was included on the pathology reports alongside the SI result for several months and even now the normal range is still printed on the form. As far as the patients are concerned they have probably benefited, since for each result one consults the normal range (until it is familiar) and perhaps converts the value to old units, thus having two to compare, although this exercise rapidly becomes unnecessary.

We do not particularly like the change. But we know of no accident occurring through misinterpretation, and despite a few snags initially the system is soon used fluently-as was decimal currency.

ANDREW CROWTHER BRIAN GRAY

Tewkesbury

ROBERT ROGERS

Cheltenham, Glos

Penicillin-"sensitive" methicillin-resistant Staphylococcus aureus

SIR,-The last sentence in Mr D F J Brown's letter ( 8 November, p 344) must be disputed. He states that "methicillin-resistant strains should be reported penicillin-resistant even if apparently penicillin-sensitive when tested at $37^{\circ} \mathrm{C}$." Perhaps I am naive in thinking that the purpose of the laboratory sensitivity testing is to predict the outcome of therapy in vivo. But surely to discount apparent sensitivity in vitro at $37^{\circ} \mathrm{C}$ makes all sensitivity testing superfluous? It is possible to make any organism appear resistant to almost any antibiotic in vitro by adjusting the conditions appropriately. Thus Escherichia coli is always resistant to neomycin at $\mathrm{pH} 5$, pseudomonas sensitivity to gentamicin is adversely affected by divalent metal ions, and co-trimoxazole is inactivated by thymidine.

For laboratory sensitivity testing to be useful, conditions as appropriate as possible to the in vivo situation are desirable. There is certainly doubt as to the reality of methicillin resistance in vivo. It would seem wise to report such few strains as "doubtful" rather than resistant.

\section{R W LACEY}

West Norfolk and King's Lynn General Hospital, King's Lynn, Norfolk

\section{Long-term postinfarction treatment with practolol}

SIR,-With reference to the multicentre international study on this subjeot (27 September, p 735) we wish to make the following comments.

It is gratifying that our findings ${ }^{12}$ of a reduction in the incidence of sudden death after acute myocardial infarction using alprenolol are confirmed by an independent study in which practolol was used. The authors of the multicentre study consider that beta-blocker therapy is especially indicated in patients with anterior wall infarcts.

In order to be able to apply the results and conclusions drawn from a study to other groups of patients the original patients must be representative of the general population of infarct patients. It is impossible to assess the representativeness of the patients in the multicentre study without knowing the numbers of and reasons for the exclusions. There might have been a selection of patients in this study, as reflected by the low total mortality.

The main end points used in the study were death and reinfarction. Neither of these terms is clearly defined by the authors. We are, however, uncertain where data on the patients who died more than 24 hours after the onset of symptoms and/or the last dose of practolol are presented. A large number of patients dropped out of the study and $39 \%$ of the patients who died did so after withdrawal.

If sudden death is accepted as the main end point table VI shows that it is more important to discriminate according to bloodpressure levels than site of infarct. The reduction in the incidence of sudden death was the same among patients with anterior wall infarcts and those with posterior wall infarcts. It is probable that patients with large infarcts, with a complicated clinical course and a poor prognosis, have lower blood pressures than others on discharge from hospital. The retrospective demonstration of the importance of the diastolic blood pressure seems questionable since the mortality in the group given placebo was the same in patients with high and low pressure. The meaning of results from a discriminant analysis such as this must be prospectively validated. The material presented, therefore, does not permit the conclusion that betablockade is especially favourable in cases of specific infarct location.

A reduction in sudden mortality has so far been shown for two beta-blockers only, practolol and alprenolol. Other beta-blockers should be used for this indication only when clinical trials have shown that they possess the same property.

J ANDERS VEDIN Claes E Wilhelmsson

Section for Preventive Cardiology,

Department of Medicine I,

Sahlgren's Hospital,

1 Wilhelmsson, C E, et al, Lancet, 1974, 2, 1157

Vedin, A, Wilhelmison, C, and Werkö, L,
Medica Scandinavica, 1975, suppl 575, p 1.

\section{Rheumatic heart disease in South Africa}

SIR,-The study of rheumatic heart disease (RHD) in Soweto (23 August, p 474) is an epidemiological classic. Dr M J McLaren and his colleagues have exposed the dimensions of a rampant but preventable illness. Small wonder that they should have added this monumental task to their already burdensome duties. As Professor Barlow's guest at both Johannesburg General and Baragwanath hospitals I was struck by the unbelievable numbers of quite young Black patients with every conceivable kind and complication of advanced rheumatic heart lesion.

In other Western countries we still see RHD mainly in the poor, but less and less of it and usually not in an advanced stage until at least the third decade. Because the decline in RHD began even before we had effective antimicrobials we can relate it in part to improved conditions for the urban poor, including better medical attention. Primarily, however, high prevalence of streptococcal infection and its consequences remain among the many scourges of poverty, afflictions that can be literally rooted out by socioeconomic amelioration. At the same time the physician's duty is clear: to press for massive intervention with public health measures including community education, constant case finding, and preventive treatment.

Dr McLaren and his colleagues propose a comprehensive preventive campaign against RHD while improving the lot of the Black community. For this these outstanding humanitarian scientists need no further documentation. Yet I suspect that they may need powerful support from their colleagues abroad because, as I have personally witnessed, the situation is appalling despite the efforts of the already overworked Johannesburg physicians.

DAVID H SPODICK

Department of Medicine,

Tufts University School of Medicine, Boston, Massachusetts

\section{Merrison Report and overseas doctors}

SIR,-Although the Merrison Report ${ }^{1}$ was published some months ago there has been singularly little informed discussion in public about it and its recommendations. Some interested organisations have readily accepted it and the British Medical Association wants the implementation of its recommendations. Controversial measures have already been taken on its recommendation which may have far-reaching consequences for the NHS.

I would like to draw the attention of your readers to paragraphs $181-5$ in part $C$ of the report. These deal primarily with the assessment of overseas doctors-a euphemism in this report for coloured doctors from the New Commonwealth and Middle Eastern countries-and the term is often used pejoratively. The methods of assessment and conclusions are open to serious objection on the following grounds.

(1) There was not a single member from the minority ethnic groups on the committee. (2) None of the medical members of the committee had any reasonable and personal knowledge of the cultures of the overseas doctors or personal experience of working with them in Britain or abroad. (3) Out of 140 persons and organisations listed in appendix A from whom evidence was received, there was not one single immigrant doctor or organisation representing solely overseas doctors. (4) The objective and subjective evidence described in the report would not satisfy any careful and impartial investigator. This evidence was received from chosen sectors of society-that is, the royal colleges, whose membership is well known for preconceived notions and rigid attitudes against immigrants generally-but completely ignored the consumers, the patients whom both British and overseas doctors treat. In other words, complaints were received from all other interested sources except from patients or their organisations. (5) The deputising services and other agencies which have considerable experience of working with overseas doctors will not wholly agree with the "inescapable conclusions" reached by the committee. (6) The number of complaints to family practitioner committees do not show any unduly large proportion against overseas 